\title{
The More the Merrier? The Causal Effect of High Fertility on Later-Life Loneliness in Eastern Europe
}

\author{
Thijs van den Broek ${ }^{1}$ (D) Marco Tosi ${ }^{2}$
}

Accepted: 23 December 2019 / Published online: 6 January 2020

(c) The Author(s) 2020

\begin{abstract}
Levels of later-life loneliness are high in Eastern Europe. We assess whether having more children is protective against later-life loneliness for Eastern-European mothers and fathers. Drawing on Generations and Gender Surveys data of 25,479 parents aged 50-80 from eight Eastern-European countries, we adopt an instrumental approach exploiting parents' preference for mixed-sex offspring to estimate the causal effect of having additional children on feelings of loneliness. We find that having an additional child has a causal protective effect against loneliness for mothers. Ordinary least squares regression models also show a weak but statistically significant negative association between number of children and later-life loneliness among fathers. However, results of the instrumental variable analyses are inconclusive for this group. We thus do not find statistically significant causal evidence that having an additional child is protective against loneliness for fathers. Our results underline the importance of addressing reverse causality and selection bias when investigating the links between number of children and later-life loneliness, particularly among women. The causal evidence presented here suggests that the trend towards families with fewer children noted in several Eastern-European countries may place new cohorts of older Eastern-Europeans, and in particular Eastern-European women, at risk of stronger feelings of loneliness.
\end{abstract}

Keywords Loneliness $\cdot$ Fertility $\cdot$ Causal inference $\cdot$ Ageing $\cdot$ Wellbeing $\cdot$ Instrumental variable

\section{Introduction}

It is well-established that the prevalence of loneliness among older people is relatively high in Eastern Europe (De Jong Gierveld and Tesch-Römer 2012; Hansen and Slagsvold 2016; Van den Broek et al. 2019; Yang and Victor 2011). Loneliness is the negative experience of a discrepancy between the number and quality of the relationships that one desires and those one actually has (De Jong Gierveld et al. 2006; Peplau and Perlman 1982). Given

Thijs van den Broek

vandenbroek@eshpm.eur.nl

1 Erasmus School of Health Policy and Management, Erasmus University Rotterdam, Burgemeester Oudlaan 50, 3062 PA Rotterdam, The Netherlands

2 Collegio Carlo Alberto, Piazza Arbarello 8, 10122 Turin, Italy 
that loneliness is associated with raised risks of morbidity (Courtin and Knapp 2017; Ong et al. 2016) and mortality (Holt-Lunstad et al. 2015), it is increasingly recognized as an important public health issue (Gerst-Emerson and Jayawardhana 2015).

Drawing on data from the Generations and Gender Surveys (GGS), this study aims to shed light on whether having more children is protective against later-life loneliness in Eastern Europe. As considered in further detail later, adult children can be expected to be a particularly important source of support for older people in Eastern-European countries where there are strong family norms and weak public support systems. When older Eastern-European women and men have more children, it may thus be less likely that they experience a discrepancy between the support they can derive from their network and the support they would desire.

Earlier work in which the links between fertility and loneliness has been estimated has tended to adopt a descriptive approach (e.g., De Jong Gierveld et al. 2012; Hansen and Slagsvold 2016; Stevens and Westerhof 2006; Van den Broek et al. 2019). Results from these studies should be interpreted with caution, because both fertility and loneliness are strongly socially patterned. For instance, socio-economic resources and family orientations, which are often unobserved, may affect both fertility behavior and feelings of loneliness. Therefore, estimates from previous studies may be prone to bias due to selection. Also, the commonly taken approach does not allow accounting for potential reversed causality. We extend earlier work by using the sex composition of respondents' two firstborn children as an instrumental variable. This approach allows us to estimate the causal effect of high fertility on loneliness.

\section{Theoretical Background and Hypothesis}

Loneliness can be defined as a discrepancy between the support that can be derived from one's network and the support desired. Having many children may affect both the former and the latter.

\subsection{Support Availability}

Next to spouses and partners, children are the most important source of support for older persons (Dykstra 2015; Wolff and Kasper 2006). Litwak's task specificity model (Litwak et al. 2003; Messeri et al. 1993) suggests that the particular characteristics of adult children, such as long-term internalized commitment, make them likely providers of a range of different types of support, such as emergency financial assistance and acute help during illness. Similarly, the convoy model proposed by Antonucci et al. (2003) suggests that children represent a safety net that can be activated in times of need, and that may promote feelings of reassurance among older parents who expect to be able to draw on it in times of need. Research has shown that older adults are indeed more likely to receive support when they have more children (Grundy and Read 2012; Marcil-Gratton and Légaré 1992; Uhlenberg and Cooney 1990). Adult children may also provide a sense of belonging, feelings of gratitude and opportunities for sociability (cf. Evenson and Simon 2005; Tosi and Grundy 2019). Consistent with this reasoning, Canadian older parents with more than three children have been found to be less likely to be devoid of daily social contacts than their counterparts with two or three children (Marcil-Gratton and Légaré 1992). Through the mechanism that higher fertility may result in a larger potential for older parents to derive 
support and companionship from their networks, having more children may be protective against later-life loneliness. It should be noted that Eastern European women live and age alone relatively often, due to the large gender difference in mortality in Eastern European countries (Bobak 2003). Hence, for women even more so than for men, having many children may be an "old age insurance" against loneliness and support deficit (cf. Hansen et al. 2009).

High fertility may not just expand the network of potential providers, however. It may also shrink the quantity and quality of social relations outside the family. Parents with many children have less time to maintain social contact and engage in leisure activities with friends, neighbors and colleagues. Research has shown that engagement in social activities with non-kin is higher among parents of two or three children than among parents of four or more children, particularly when they are not living with a spouse (Marcil-Gratton and Légaré 1992). Social interactions with friends and local community are based on shared values, interests and lifestyles, and provide opportunities for support and self-recognition (Adams et al. 2000). Given the characteristics of non-kin network, studies found a positive association between friendship ties and mental health (Han et al. 2019); an effect that may compensate and outweigh the one of family relationships (Fiori and Jager 2012; Huxhold et al. 2013). From these considerations it follows that parents with many children may have less interactions outside the family, which may produce higher feelings of loneliness in later life.

\subsection{Support Need}

High fertility may also result in a higher need for social and economic support, due to health issues and economic opportunity costs. Repeated pregnancy, parturition and lactation may make women who gave birth to many children vulnerable to various health problems in later life. Research indicates that so-called grandmultiparous women-typically defined as mothers of at least four or five children-are at increased risk of a range of diseases, including diabetes (Nicholson et al. 2006; Vandenheede et al. 2012), cardiovascular disease (Durazo et al. 2018; Parikh et al. 2010), cervical cancer (Grundy and Kravdal 2010), and of reporting poor self-rated health (Kington et al. 1997). Additionally, raising children may jeopardize women's employment careers and reduce their chances of obtaining higher salaries and prestigious occupations. A recent meta-analysis of research on the so-called motherhood penalty showed that high fertility was associated with lower wages for women (Cukrowska-Torzewska and Matysiak 2018), which may result in financial problems in later life (cf. Hank and Wagner 2013).

Although the above mentioned mechanisms are particularly salient for women, adverse effects of high fertility have also been reported for men (e.g., Grundy and Tomassini 2006). Keenan and Grundy (2018) argued that the cumulative stress and financial strain associated with raising many children may partly explain the finding that both mothers and fathers of four or more children had poorer physical and psychological health than their counterparts with two children (cf. Read et al. 2011). Consistent with this reasoning, Hank and Wagner (2013) found that European older mothers and fathers of four or more children had a relatively high risk of experiencing financial strain. Moreover, Grundy and Read (2015) showed that allostatic load, a marker of repeated or chronic exposure to stress (McEwen and Seeman 1999; McEwen and Stellar 1993), was higher among older English mothers and fathers of four or more children than among their counterparts with two children. The 
higher need for practical, emotional and financial support that parents may experience when they have more children could alter the equilibrium between support received and desired, and thus trigger stronger feelings of loneliness.

Additionally, higher fertility may affect loneliness by shaping expectations about social support. Parents with many children may have higher expectations of receiving support and companionship, and a "normal" level of support may countervail such expectations. Moreover, they spend a longer part of their lives living with at least one child at home, and the transition to an 'empty nest', where no children are co-resident, may be particularly detrimental (Tosi and Grundy 2018; White and Edwards 1990). This suggests that parents with many children may feel particularly lonely when all children leave the household.

\subsection{Eastern-European Context}

Whether or not potential protective effects of many children are stronger than potential harmful effects may depend on context. The focus of the current study is on Eastern-European countries where levels of defamilialisation, i.e. "independence from family support for the satisfaction of one's own needs" (Saraceno and Keck 2011, p. 374) are relatively low, given the limited availability of publicly provided alternatives for family-provided care and support to older persons in need (Saraceno 2010). Long-term care systems in most Eastern-European countries are characterized by fragmentation, inadequate infrastructures and a lack of financial resources (Österle 2010, 2012). Also, filial responsibility and obligations to support older parents tend to be relatively strong in Eastern Europe (Daatland et al. 2011; Österle 2010). Consequently, close family members cover most of the support needs of older persons with health limitations (Österle 2010). Additionally, the substantial erosion of the value of the relatively generous and near universal pensions has contributed to the impoverishment of many older Eastern-Europeans (Buckley and Donahue 2000; Laczko 1994). All this may make the dependence of older persons on their children relatively strong in Eastern Europe.

Consistent with this reasoning, Grundy et al. (2019) recently showed that the links between fertility and psycho-social wellbeing were stronger in Eastern Europe than in Western Europe. Similarly, Mair (2013) found that the protective effect of family ties on older adults' health was particularly strong in Southern-European and Eastern-European countries, where a familialistic culture and low pension spending promoted family interdependence. Given that Eastern-European cultural and policy contexts foster a strong reliance of older people on close family, we expect the benefits of high fertility to outweigh the negative implications. We therefore hypothesize that, in the context studied here, having more children is protective against feelings of loneliness in later life.

\section{Observational Studies, Selection and Reverse Causality Bias}

Many studies on the impact of fertility on later-life loneliness compared parents and their childless counterparts (e.g., Hansen et al. 2009; Koropeckyj-Cox 1998; Van den Broek 2017; Vozikaki et al. 2018; Zhang and Hayward 2001). Scholars assessing loneliness differences among parents have tended to focus on the role of differences in the frequency of contact with children (Fokkema et al. 2012; Pinquart 2003; Routasalo et al. 2006), the quality of the relationship with children (Koropeckyj-Cox 2002; Long and Martin 2000) or the geographical distance to children (Van den Broek and Grundy 2017). Compared to 
these qualitative aspects of parenthood, the links between number of children and loneliness-the focus of the current study-have received little scholarly attention. The small body of research in which these links have been assessed tends to show a weak negative association between number of children and feelings of loneliness in later life (De Jong Gierveld et al. 2012; De Jong Gierveld and Van Tilburg 2010; Hansen and Slagsvold 2016; Pinquart and Sörensen 2001; Van den Broek et al. 2019). Null-findings have, however, also been reported for the combined Bulgarian/Russian/Georgian subsample in one study (De Jong Gierveld et al. 2012) and for Dutch and German samples in other studies (De Jong Gierveld et al. 2009; Stevens and Westerhof 2006).

A problem in the estimation of the effects of number of children is that fertility is highly selective. Earlier research has, for instance, showed notable differences in fertility patterns by education, religiosity and family background (Mencarini and Tanturri 2006). Completed fertility is associated with the timing of the transition to parenthood, educational attainment and socio-economic position (Isen and Stevenson 2010; Kravdal and Rindfuss 2008). The lower educated tend to become mothers early and are more prone to have many children. Conversely, highly educated women are more likely to delay entry into motherhood to pursue high-qualified careers (Nicoletti and Tanturri 2008), and are often socialized to cultural orientations that place less emphasis on motherhood and stress the importance of self-realization (Mencarini and Tanturri 2006). Education and socio-economic resources are, in turn, protective against loneliness (Victor et al. 2005). Not accounting correctly for these common antecedents can therefore introduce selection bias in the estimated effect of fertility on later-life loneliness. The approach typically taken to reduce this risk of omitted variable bias is to adjust for a range of control variables. However, this approach rests on the rather bold assumption that all potentially confounding variables are correctly included in the model specification. Moreover, potential reversed causality cannot be accounted for in the conventional strategy. People with a tendency to feel lonely may have difficulties to establish stable partner relationships. If this, in turn, results in lower fertility levels, then the causal direction of the association between fertility and feelings of loneliness may be opposite of what is typically assumed.

Studies addressing selection and reverse causality bias have used twin births and/or parents' preference for mixed-sex offspring as instruments to identify causal effects of fertility on children's outcomes (e.g., Angrist et al. 2010; Conley and Glauber 2006). However, only few studies have adopted this strategy to analyze older parents' psychosocial wellbeing. An exception is a study by Kruk and Reinhold (2014), who estimated the causal effects of additional children on depressive symptoms among older women and men in 13 European countries. They did not find statistically significant evidence that having an additional child was protective against depressive symptoms among fathers. Their results for mothers were mixed, with some evidence that having more children was associated with increased depression risks. In the current study, we will adopt a largely similar strategy to estimate the causal effect of high fertility on feelings of loneliness among older mothers and fathers in Eastern Europe.

\section{Analytical Strategy}

As argued above, the strong patterning of both high fertility and loneliness makes it challenging to adequately account for all potential confounding variables. In addition to straightforward ordinary least squares regression models in which we regress loneliness on 
number of children as observed and assume that the latter variable is exogenous, we therefore adopt an instrumental variable approach (Angrist and Pischke 2009). Following Kruk and Reinhold (2014), we exploit the preference for mixed-sex offspring that is present in many countries. Indicative of the preference for mixed-sex offspring is the finding reported in multiple demographic studies that parents of two children are more likely to have a third child when the two firstborn children are either both girls or both boys than when they are a girl and a boy (Andersson et al. 2006; Hank and Kohler 2000; Mills and Begall 2010). Therefore, the former group of parents may have higher completed fertility than the latter. Given that this fertility difference is attributable to whether the sex of the second child is different from the sex of the first child, it is effectively randomly assigned by nature and therefore exogenous. We exploit this random assignment to estimate a causal effect of having more children on loneliness. This is done in a two-stage approach. Equation 1 presents the first stage model:

$$
X_{i}=\alpha_{0}+\alpha_{1} Z_{i}+\varepsilon_{i}
$$

In the first stage, the number of children $X$ for person $i$ is regressed on the exogenous instrument $Z$, i.e. whether or not the two firstborn children of individual $i$ having the same sex. Estimate $\alpha_{1}$ denotes the surplus number of children that, due to the preference for mixed-sex offspring, parents whose two firstborn children are of the same sex have over parents whose two firstborn children are of different sexes. This exogenous fertility difference is subsequently used in the second stage to estimate the causal effect of having more children on loneliness. The second stage is presented in Eq. 2. Here, loneliness $Y$ for individual $i$ is regressed on the number of children as predicted in the first stage $X$.

$$
Y_{i}=\beta_{0}+\beta_{1} \hat{X}_{i}+u_{i}
$$

We estimate the instrumental variable models using two stage least squares regression with robust standard errors to account for the nested nature of our data (White 1980). Given that antecedents of loneliness are known to differ between women and men (Dahlberg et al. 2015; Van den Broek 2017), all estimated models are stratified by gender.

\section{Data}

\subsection{Sample}

Data used are from Wave 1 of the Generations and Gender Surveys (GGS, see www.ggp-i. org). The GGS is a cross-national survey of nationally representative samples of the adult population of up to 80 years old (Vikat et al. 2007). We restricted our sample to parents of at least two biological children who were between 50 and 80 years old from eight Eastern-European countries: Bulgaria, Czech Republic, Estonia, Georgia, Lithuania, Poland, Romania, and Russia $(n=26,868)$. We did not use the Hungarian sample, because information on loneliness was not collected in this country. Response rates varied between $36 \%$ for the Lithuanian sample and $84 \%$ for the Romanian sample (Fokkema et al. 2016). Supplied country-specific weights were used to adjust for selective nonresponse (Fokkema et al. 2016).

Respondents with missing information on loneliness $(n=212)$, the sex of at least one of the oldest two children $(n=44)$, or the birth year of at least one of their children $(n=443)$ were excluded. We also excluded respondents without a valid analytical weight $(n=7)$ and 
respondents who reported having non-biological children $(n=427)$. Finally, we dropped respondents with three or more children whose second and third child were born in the same year $(n=327)$. We did so, because for these respondents the instrument used in this study could not be properly coded. After these exclusions, a final analytical sample of 14,807 mothers and 10,672 fathers remained.

\subsection{Measures}

Loneliness was measured with the six-item version of the De Jong Gierveld loneliness scale (De Jong Gierveld and Van Tilburg 2006). This is a shortened version of the full 11-item version that has been recommended for research involving middle-aged and older adults (Penning et al. 2014). The shortened De Jong Gierveld loneliness scale consists of three positively formulated items ("There are plenty of people that I can lean on in case of trouble", "There are many people that I can count on completely", and "There are enough people that I feel close to") and three negatively formulated items ("I experience a general sense of emptiness", "I miss having people around", and "Often, I feel rejected"). Respondents are asked to what extent each of the statements applies to the current state of their lives, with response categories being "yes", "no" or "more or less". As prescribed by the developers of the scale (De Jong Gierveld and Van Tilburg 1999), we derived a loneliness scale score ranging from 0 (not lonely) to 6 (intensely lonely) by summing the neutral and positive answers ("more or less", "yes") on the negatively formulated items and neutral and negative answers ("more or less", "no") on the positively formulated items. The internal consistency of the scale was satisfactory in our sample $($ KR-20 $=0.75)$.

Our explanatory variable of interest is number of biological children. For our regression analyses, we deducted 2-the minimal number of biological children for the parents in our sample-from the total number of biological children in order to facilitate an easier interpretation of the estimated intercepts in our models. The instrument used to predict this plausibly endogenous variable is a variable capturing the sex composition of respondents' two firstborn children. This variable is dichotomous and distinguishes parents of whom the two firstborn children are of the identical sex (girl-girl or boy-boy) from their counterparts of whom the two firstborn children are of a different sex (girl-boy or boy-girl). ${ }^{1}$ This instrument is exogenous, because it is randomly assigned by nature whether or not the sex of the second child is identical to the sex of the first child. Consequently, there is no need to include additional control variables in our models. Descriptive statistics for the sample used are presented in Table 1.

\section{Results}

Results of ordinary least squares regression models and two-stage least squares models predicting loneliness measured with the short De Jong Gierveld loneliness scale are presented in Table 2. The results for mothers are shown in the upper part of the table. The bottom part of the table shows the results for fathers.

\footnotetext{
1 In preliminary analyses we also used an alternative specification in which parents with two boys and parents with two girls as their firstborn children were distinguished. This specification did not perform better than the more parsimonious specification used. Substantive results of the instrumental variable analyses of the effects of additional children on loneliness were very similar in both specifications.
} 
Table 1 Sample characteristics; means and percentages

\begin{tabular}{lll}
\hline & Women & Men \\
\hline Short DJG loneliness score & 2.4 & 2.4 \\
(Standard deviation) & $(1.9)$ & $(1.8)$ \\
Number of children & 2.6 & 2.5 \\
(Standard deviation) & $(1.0)$ & $(0.9)$ \\
Sex composition two firstborn children: & & \\
Identical & $50.1 \%$ & $51.4 \%$ \\
Different & $49.9 \%$ & $48.6 \%$ \\
Age & 62.8 & 62.4 \\
(SD) & $(8.3)$ & $(8.2)$ \\
Country & & \\
Bulgaria & $14.4 \%$ & $16.6 \%$ \\
Czech Republic & $9.0 \%$ & $9.4 \%$ \\
Estonia & $10.4 \%$ & $9.0 \%$ \\
Georgia & $11.1 \%$ & $12.2 \%$ \\
Lithuania & $9.2 \%$ & $8.7 \%$ \\
Poland & $22.0 \%$ & $22.1 \%$ \\
Romania & $11.5 \%$ & $12.5 \%$ \\
Russia & $12.4 \%$ & $9.5 \%$ \\
Number of observations & 14,807 & 10,672 \\
\hline
\end{tabular}

Data are from generations and gender surveys, Wave 1; Weighted

Table 2 Results of ordinary least squares regression models and two-stage least squares models predicting loneliness (short De Jong Gierveld loneliness scale)

\begin{tabular}{|c|c|c|c|c|c|c|}
\hline & \multicolumn{2}{|l|}{ OLS } & \multicolumn{2}{|l|}{ First stage } & \multicolumn{2}{|c|}{ Second stage } \\
\hline & Coeff. & (SE) & Coeff. & (SE) & Coeff. & (SE) \\
\hline \multicolumn{7}{|l|}{ Women $(N=14,807)$} \\
\hline Number of children & -0.024 & $(0.015)$ & & & $-0.906^{*}$ & $(0.404)$ \\
\hline \multicolumn{7}{|c|}{ Sex composition two firstborn children: } \\
\hline Identical & & & Ref. & & & \\
\hline Different & & & $-0.091 * * *$ & $(0.018)$ & & \\
\hline Constant & $2.426 * * *$ & $(0.018)$ & $0.617 * * *$ & $(0.013)$ & $2.931 * * *$ & $(0.231)$ \\
\hline \multicolumn{7}{|l|}{$\operatorname{Men}(N=10,672)$} \\
\hline Number of children & $-0.045^{*}$ & $(0.019)$ & & & -0.454 & $(0.374)$ \\
\hline \multicolumn{7}{|c|}{ Sex composition two firstborn children: } \\
\hline Identical & & & Ref. & & & \\
\hline Different & & & $-0.100 * * *$ & $(0.018)$ & & \\
\hline Constant & $2.377 * * *$ & $(0.018)$ & $0.565 * * *$ & $(0.013)$ & $2.588 * * *$ & $(0.194)$ \\
\hline
\end{tabular}

Data are from generations and gender surveys, Wave 1; Weighted ${ }^{*} p<0.05, * * p<0.01, * * * p<0.001$ 


\subsection{Mothers}

The first model is a naive ordinary least squares model in which the estimated negative association between number of children and feelings of loneliness was very small in magnitude and not statistically significant. As considered earlier, however, the assumption underlying this model that number of children is an exogenous variable may be overly bold, and it should be considered that the effect may be underestimated due to unobserved suppressors.

The second model shown in Table 2 is the first-stage model of our instrumental variable model. It shows that mothers of two or more children whose two firstborn children were of the same sex had on average 0.09 children more than their counterparts whose two firstborn children were of two different sexes. The F-statistic greatly exceeded 10, indicating that the instrument used in the first stage (sex composition of the two firstborn children) strongly predicted the instrumented variable (total number of children) $(F(1,14805)=26.9, p<0.001)$. The third model presented is the second stage of our instrumental variable model. Here, the exogenous fertility difference between mothers whose two firstborn children were of two different sexes and mothers whose two firstborn children were of the same sex estimated in the first stage was used to estimate the causal effect of number of children on feelings of loneliness. Results indicate that an additional child had a substantial protective effect against loneliness. A robust score Chi-squared test indicated that the estimates of the two-stage least squares model were to be preferred over the estimates of the naive ordinary least squares model, because the assumption of exogeneity underlying the latter model was violated $\left(\chi^{2}(1, N=14,807)=6.6, p<0.05\right)$. Our analyses thus provide causal evidence that having more children is protective against later-life loneliness for mothers in Eastern Europe.

\subsection{Fathers}

The naive ordinary least squares model for men showed a small, but statistically significant association between number of children and loneliness. The first-stage model of our instrumental variable model showed that fathers of at least two children had on average 0.10 children more when their two firstborn children were of the same sex as opposed to when they were of mixed sexes. As was the case in the sample of mothers, the instrument was a sufficiently strong predictor of total number of children $(F(1$, $10,670)=29.5, p<0.001)$.

The estimated effect of number of children on feelings of loneliness was considerably larger in magnitude in the second stage of our instrumental variable model than in the naive ordinary least squares model. However, it was not statistically significant. A robust score Chi-squared test did not provide statistically significant evidence that the exogeneity assumption underlying the naive model was violated $\left(\chi^{2}(1\right.$, $N=10,669)=1.3, p=0.26)$. Consequently, we did not have any reason to prefer the estimates of the instrumental variable model over the more precise estimates of the naive model. Our analyses thus suggest that having more children may also be protective against later-life loneliness among fathers in Eastern Europe. Given the inconclusiveness of the instrumental variable results, causality cannot be inferred from these findings, however. 


\section{Discussion}

Drawing on GGS data of 25,479 parents aged 50-80 from eight Eastern-European countries, we assessed whether having more children is protective against later-life loneliness for Eastern-European mothers and fathers. The small body of research in which the link between number of children and later-life loneliness has been assessed typically adopted a descriptive approach, making findings prone to bias due to selection or reverse causality. In contrast to earlier work, we adopted an instrumental variable approach exploiting people's preference for mixed-sex offspring. This allowed us to estimate the causal effect of high fertility on loneliness.

For mothers, but not fathers, we found causal evidence that having more children was protective against later-life loneliness. Given that children are important sources of support and companionship for older mothers, higher fertility may reduce the discrepancy between the support derived and desired. Although mothers with many children tend to have a higher need of financial and care support (Cukrowska-Torzewska and Matysiak 2018; Kington et al. 1997), they can rely on children's availability. In our analyses of loneliness, the positive effect of higher fertility on the opportunity of receiving support appears to outweigh its negative implications. The results of our analyses suggest that the magnitude of the effect of an additional child on mothers' feelings of loneliness in later life is large: one additional child was associated with an estimated decline in feelings of loneliness of approximately half a standard deviation. It is worth noting, however, that the confidence intervals were rather large, which means that the true effect in the population could be considerably smaller.

Previous descriptive findings have suggested that higher fertility may have either weak or no protective effects on parents' feelings of loneliness (De Jong Gierveld et al. 2012; De Jong Gierveld and Van Tilburg 2010; Stevens and Westerhof 2006). Our naive ordinary least squares model of later-life loneliness among mothers also did not provide evidence for such an effect. However, we showed that the effect of additional children was significantly underestimated in this model. Several factors known from the literature to be protective against loneliness, e.g., high socio-economic status (Van den Broek et al. 2019; Victor et al. 2005), are traditionally also associated with lower completed fertility (Isen and Stevenson 2010; Kravdal and Rindfuss 2008). Failure to properly account for such factors will result in underestimation of the impact of high fertility on later-life loneliness. In some cases, this issue can be adequately addressed by including control variables in multivariate regression models. However, potential confounders or suppressors that are difficult to observe, e.g., personality traits, call for more inventive ways of addressing reverse causality and selection bias when investigating the links between number of children and laterlife loneliness, for instance an instrumental variable approach such as taken in the current study.

In a study using instrumental variable approach, Kruk and Reinhold (2014) showed some evidence that mothers with more children had more depressive symptoms in a number of European countries. It should be noted that depression and loneliness are distinct concepts (Weeks et al. 1980). Compared to depression, loneliness has a meaning that is more strongly linked to the actual and desired network of support, which is more sensitive to family size. This may explain the apparent discrepancy between our findings and those of Kruk and Reinhold (2014). Within the concept of loneliness, a distinction is sometimes made between emotional and social loneliness (De Jong Gierveld and Van Tilburg 2006; Weiss 1973). The former refers to the lack of a close bond of confidant, and the latter to a 
lack of contact. Additional analyses (full results available on request) suggested that number of children particularly affects social loneliness, but more research is needed to make conclusive statements about potential differences in the impact of high fertility on social loneliness and on emotional loneliness.

A few limitations of the current study should be considered. The estimates produced by our instrumental variable approach are unbiased, but relatively unprecise, i.e. confidence intervals are large. As a consequence of this lack of precision, the coefficient estimate of an additional child in the instrumental variable model for fathers is statistically indistinguishable from both zero and the statistically significant negative coefficient estimate produced by the naïve ordinary least squares regression model. Therefore, we cannot be conclusive about a possible causal protective effect of having additional children among EasternEuropean fathers. Moreover, our approach necessitated us to only include parents of two or more children in our analytical sample. Therefore, the estimated causal effects of additional children on later-life loneliness may be different from the true effects of first and second children. Plausibly, these effects are larger than the effects presented here, given that there is evidence to suggest diminishing returns of additional adult children for older parents (e.g., Grundy et al. 2019). Also, the instrument used exploits that older Eastern-European parents were more likely to plan to have an additional child when they did not have either a daughter or a son among their two firstborn children. This comes with the caveat that it does not predict additional unplanned children. The causal effects of additional children on later-life loneliness estimated in the instrumental variable models presented here are thus not valid for unplanned children.

We examined eight Eastern-European countries, where older persons have to rely on offspring for their welfare and where gender and family norms tend to be traditional (Guetto et al. 2015; cf. Jappens and Van Bavel 2012). It would be interesting to test whether the causal protective effect of higher fertility on loneliness was weaker in Western-European countries where levels of de-familialization are higher (Saraceno 2010). However, in this study we focused on a relatively homogeneous context where traditional family and gender attitudes make a relatively strong preference for mixed-sex offspring likely ${ }^{2}$ (cf. Pollard and Morgan 2002). Further research is needed to identify variation across (clusters of) countries in the causal effect of higher fertility.

Despite these limitations, our finding that having an additional child had a causal protective effect against later-life loneliness among Eastern-European mothers is important. In several Eastern-European countries, such as Bulgaria and Russia, a trend towards families with fewer children has been noted (Philipov and Kohler 2001; Sobotka 2003). Our results suggest that this trend may place new cohorts of older Eastern-European women at increased risk of loneliness.

Acknowledgements The authors gratefully acknowledge the financial support provided by COST Action IS1409 Funded by the EU Framework Programme for Research and Innovation Horizon2020 for the second author's research visit to the Erasmus School of Health Policy and Management.

\footnotetext{
${ }^{2}$ Gender norms are less traditional in Western-European countries. This can be expected to correspond with a weaker preference for mixed-sex offspring (Pollard and Morgan 2002), and consequently with a lower strength for the instrument used in this study. Preliminary analyses performed on data from six Western-European countries for which all relevant variables were available in the GGS (Belgium, France, Germany, Netherlands, Norway and Sweden) showed that our instrument indeed met conventional strength standards neither among mothers $(\mathrm{F}(1,8223)=4.0)$, nor among fathers $(\mathrm{F}(1,7402)=8.4)$.
} 
Open Access This article is licensed under a Creative Commons Attribution 4.0 International License, which permits use, sharing, adaptation, distribution and reproduction in any medium or format, as long as you give appropriate credit to the original author(s) and the source, provide a link to the Creative Commons licence, and indicate if changes were made. The images or other third party material in this article are included in the article's Creative Commons licence, unless indicated otherwise in a credit line to the material. If material is not included in the article's Creative Commons licence and your intended use is not permitted by statutory regulation or exceeds the permitted use, you will need to obtain permission directly from the copyright holder. To view a copy of this licence, visit http://creativecommons.org/licenses/by/4.0/.

\section{References}

Adams, R. G., Blieszner, R., \& De Vries, B. (2000). Definitions of friendship in the third age: age, gender, and study location effects. Journal of Aging Studies, 14(1), 117-133. https://doi.org/10.1016/ S0890-4065(00)80019-5.

Andersson, G., Hank, K., Ronsen, M., \& Vikat, A. (2006). Gendering family composition: Sex preferences for children and childbearing behavior in the Nordic countries. Demography, 43(2), 255-267. https://doi.org/10.1353/dem.2006.0010.

Angrist, J. D., Lavy, V., \& Schlosser, A. (2010). Multiple experiments for the causal link between the quantity and quality of children. Journal of Labor Economics, 28(4), 773-824. https://doi. org/10.1086/653830.

Angrist, J. D., \& Pischke, J.-S. (2009). Mostly harmless econometrics: An empiricist's companion. Princeton, NJ: Princeton University Press.

Antonucci, T. C., Ajrouch, K. J., \& Janevic, M. R. (2003). The effect of social relations with children on the education-health link in men and women aged 40 and over. Social Science and Medicine, 56(5), 949-960. https://doi.org/10.1016/S0277-9536(02)00099-0.

Bobak, M. (2003). Relative and absolute gender gap in all-cause mortality in Europe and the contribution of smoking. European Journal of Epidemiology, 18(1), 15-18. https://doi.org/10.1023/A:10225 56718939.

Buckley, C., \& Donahue, D. (2000). Promises to keep: Pension provision in the Russian Federation. In M. G. Field \& J. L. Twigg (Eds.), Russia's torn safety nets: Health and social wellfare during the transition (pp. 251-270). New York: Palgrave Macmillan. https://doi.org/10.1007/978-1-349-62712 -7 - 13 .

Conley, D., \& Glauber, R. (2006). Parental educational investment and children's academic risk: Estimates of the impact of sibship size and birth order from exogenous variation in fertility. Journal of Human Resources, XLI(4), 722-737. https://doi.org/10.3368/jhr.XLI.4.722.

Courtin, E., \& Knapp, M. (2017). Social isolation, loneliness and health in old age: A scoping review. Health and Social Care in the Community, 25(3), 799-812. https://doi.org/10.1111/hsc.12311.

Cukrowska-Torzewska, E., \& Matysiak, A. (2018). The motherhood wage penalty: A meta-analysis. Vienna Institute of Demography Working Paper 08/2018. Vienna: Vienna Institute of Demography.

Daatland, S. O., Herlofson, K., \& Lima, I. A. (2011). Balancing generations: on the strength and character of family norms in the West and East of Europe. Ageing and Society, 31, 1159-1179. https://doi. org/10.1017/S0144686X10001315.

Dahlberg, L., Andersson, L., McKee, K. J., \& Lennartsson, C. (2015). Predictors of loneliness among older women and men in Sweden: A national longitudinal study. Aging and Mental Health, 19(5), 409-417. https://doi.org/10.1080/13607863.2014.944091.

De Gierveld, J. J., Dykstra, P. A., \& Schenk, N. (2012). Living arrangements, intergenerational support types and older adult loneliness in Eastern and Western Europe. Demographic Research, 27, 167-200. https://doi.org/10.4054/DemRes.2012.27.7.

De Gierveld, J. J., \& Tesch-Römer, C. (2012). Loneliness in old age in Eastern and Western European societies: Theoretical perspectives. European Journal of Ageing. https://doi.org/10.1007/s1043 3-012-0248-2.

De Gierveld, J. J., van Groenou, M. B., Hoogendoorn, A. W., \& Smit, J. H. (2009). Quality of marriages in later life and emotional and social loneliness. The Journals of Gerontology: Series B, 64B(4), 497-506. https://doi.org/10.1093/geronb/gbn043.

De Gierveld, J. J., \& Van Tilburg, T. (1999). Manual of the loneliness scale. Amsterdam: Vrije Universiteit.

De Gierveld, J. J., \& Van Tilburg, T. (2006). A 6-Item scale for overall, emotional, and social loneliness. Research on Aging, 28(5), 582-598. https://doi.org/10.1177/0164027506289723. 
De Gierveld, J. J., \& Van Tilburg, T. (2010). The De Jong Gierveld short scales for emotional and social loneliness: Tested on data from 7 countries in the UN generations and gender surveys. European Journal of Ageing, 7(2), 121-130. https://doi.org/10.1007/s10433-010-0144-6.

De Gierveld, J. J., Van Tilburg, T., \& Dykstra, P. A. (2006). Loneliness and social isolation. In A. L. Vangelisti \& D. Perlman (Eds.), Cambridge handbook of personal relationships (pp. 485-500). Cambridge: Cambridge University Press.

Durazo, E. M., de Baca, T. C., Slopen, N., Parikh, N. I., Buring, J. E., Glynn, R. J., et al. (2018). Parity, job strain, and cardiovascular risk in the Women's Health Study. Current Cardiovascular Risk Reports, 12(3), 8. https://doi.org/10.1007/s12170-018-0571-z.

Dykstra, P. A. (2015). Aging and social support. In G. Ritzer (Ed.), The Blackwell encyclopedia of sociology (pp. 88-93). Oxford: Blackwell.

Evenson, R. J., \& Simon, R. W. (2005). Clarifying the relationship between parenthood and depression. Journal of Health and Social Behavior, 46(4), 341-358. https://doi.org/10.1177/002214650504600 403.

Fiori, K. L., \& Jager, J. (2012). The impact of social support networks on mental and physical health in the transition to older adulthood: A longitudinal, pattern-centered approach. International Journal of Behavioral Development, 36(2), 117-129. https://doi.org/10.1177/0165025411424089.

Fokkema, T., De Jong Gierveld, J., \& Dykstra, P. A. (2012). Cross-national differences in older adult loneliness. The Journal of Psychology, 146(1-2), 201-228. https://doi.org/10.1080/00223 980.2011.631612.

Fokkema, T., Kveder, A., Hiekel, N., Emery, T., \& Liefbroer, A. C. (2016). Generations and Gender Programme Wave 1 data collection: An overview and assessment of sampling and fieldwork methods, weighting procedures, and cross-sectional representativeness. Demographic Research, 34(18), 499-524. https://doi.org/10.4054/DemRes.2016.34.18.

Gerst-Emerson, K., \& Jayawardhana, J. (2015). Loneliness as a public health issue: The impact of loneliness on health care utilization among older adults. American Journal of Public Health, 105(5), 1013-1019. https://doi.org/10.2105/AJPH.2014.302427.

Grundy, E., \& Kravdal, Ø. (2010). Fertility history and cause-specific mortality: A register-based analysis of complete cohorts of Norwegian women and men. Social Science and Medicine, 70(11), 1847-1857. https://doi.org/10.1016/j.socscimed.2010.02.004.

Grundy, E., \& Read, S. (2012). Social contacts and receipt of help among older people in England: Are there benefits of having more children? The Journals of Gerontology Series B: Psychological Sciences and Social Sciences, 67(6), 742-754. https://doi.org/10.1093/geronb/gbs082.

Grundy, E., \& Read, S. (2015). Pathways from fertility history to later life health: Results from analyses of the English Longitudinal Study of Ageing. Demographic Research, 32(1), 107-146. https://doi. org/10.4054/DemRes.2015.32.4.

Grundy, E., \& Tomassini, C. (2006). Fatherhood history and later life health and mortality in England and Wales: A record linkage study. Social Biology, 53(3-4), 189-205. https://doi. org/10.1080/19485565.2006.9989126.

Grundy, E., Van den Broek, T., \& Keenan, K. (2019). Number of children, partnership status, and laterlife depression in Eastern and Western Europe. The Journals of Gerontology, Series B, 74(2), 353363. https://doi.org/10.1093/geronb/gbx050.

Guetto, R., Luijkx, R., \& Scherer, S. (2015). Religiosity, gender attitudes and women's labour market participation and fertility decisions in Europe. Acta Sociologica, 58(2), 155-172. https://doi. org/10.1177/0001699315573335.

Han, S. H., Kim, K., \& Burr, J. A. (2019). Friendship and depression among couples in later life: The moderating effects of marital quality. The Journals of Gerontology: Series B, 74(2), 222-231. https ://doi.org/10.1093/geronb/gbx046.

Hank, K., \& Kohler, H.-P. (2000). Gender preferences for children in Europe: Empirical results from 17 FFS countries. Demographic Research. https://doi.org/10.4054/DemRes.2000.2.1.

Hank, K., \& Wagner, M. (2013). Parenthood, marital status, and well-being in later life: Evidence from SHARE. Social Indicators Research, 114(2), 639-653. https://doi.org/10.1007/s11205-012-0166-x.

Hansen, T., \& Slagsvold, B. (2016). Late-life loneliness in 11 European countries: Results from the Generations and Gender Survey. Social Indicators Research, 129(1), 445-464. https://doi.org/10.1007/ s11205-015-1111-6.

Hansen, T., Slagsvold, B., \& Moum, T. (2009). Childlessness and psychological well-being in midlife and old age: An examination of parental status effects across a range of outcomes. Social Indicators Research, 94(2), 343-362. https://doi.org/10.1007/s11205-008-9426-1. 
Holt-Lunstad, J., Smith, T. B., Baker, M., Harris, T., \& Stephenson, D. (2015). Loneliness and social isolation as risk factors for mortality: A meta-analytic review. Perspectives on Psychological Science, 10(2), 227-237. https://doi.org/10.1177/1745691614568352.

Huxhold, O., Miche, M., \& Schüz, B. (2013). Benefits of having friends in older ages: Differential effects of informal social activities on well-being in middle-aged and older adults. The Journals of Gerontology: Series B, 69(3), 366-375. https://doi.org/10.1093/geronb/gbt029.

Isen, A., \& Stevenson, B. (2010). Women's education and family behavior: Trends in marriage, divorce and fertility. In NBER working paper 15725. Cambridge, MA: National Bureau of Economic Research.

Jappens, M., \& Van Bavel, J. (2012). Regional family cultures and child care by grandparents in Europe. Demographic Research, S11(4), 85-120. https://doi.org/10.4054/DemRes.2012.27.4.

Keenan, K., \& Grundy, E. (2018). Fertility history and physical and mental health changes in European older adults. European Journal of Population. https://doi.org/10.1007/s10680-018-9489-x.

Kington, R., Lillard, L., \& Rogowski, J. (1997). Reproductive history, socioeconomic status, and selfreported health status of women aged 50 years or older. American Journal of Public Health, 87(1), 33-37. https://doi.org/10.2105/AJPH.87.1.33.

Koropeckyj-Cox, T. (1998). Loneliness and depression in middle and old age: Are the childless more vulnerable? The Journals of Gerontology Series B: Psychological Sciences and Social Sciences, 53B(6), S303-S312. https://doi.org/10.1093/geronb/53B.6.S303.

Koropeckyj-Cox, T. (2002). Beyond parental status: Psychological well-being in middle and old age. Journal of Marriage and Family, 64(4), 957-971. https://doi.org/10.1111/j.1741-3737.2002.00957.x.

Kravdal, Ø., \& Rindfuss, R. R. (2008). Changing relationships between education and fertility: A study of women and men born 1940 to 1964. American Sociological Review, 73(5), 854-873. https://doi. org/10.1177/000312240807300508.

Kruk, K. E., \& Reinhold, S. (2014). The effect of children on depression in old age. Social Science and Medicine, 100, 1-11. https://doi.org/10.1016/j.socscimed.2013.09.003.

Laczko, F. (1994). Older people in East and Central Europe: The prize of transition to a market economy. London: HelpAge International.

Litwak, E., Silverstein, M., Bengtson, V. L., \& Hurst, Y. W. (2003). Theories about families, organizations and social supports. In V. L. Bengtson \& A. Lowenstein (Eds.), Global ageing and challenges to families (pp. 27-53). Hawthorne, NY: Aldine de Gruyter.

Long, M. V., \& Martin, P. (2000). Personality, relationship closeness, and loneliness of oldest old adults and their children. The Journals of Gerontology: Series B, 55(5), P311-P319. https://doi.org/10.1093/ geronb/55.5.P311.

Mair, C. A. (2013). Family ties and health cross-nationally: The contextualizing role of familistic culture and public pension spending in Europe. The Journals of Gerontology Series B: Psychological Sciences and Social Sciences, 68(6), 984-996. https://doi.org/10.1093/geronb/gbt085.

Marcil-Gratton, N., \& Légaré, J. (1992). Will reduced fertility lead to greater isolation in old age for tomorrow's elderly? Canadian Journal on Aging, 11(1), 54-71. https://doi.org/10.1017/S07149808000145 25.

McEwen, B. S., \& Seeman, T. (1999). Protective and damaging effects of mediators of stress: Elaborating and testing the concepts of allostasis and allostatic load. Annals of the New York Academy of Sciences, 896(1), 30-47. https://doi.org/10.1111/j.1749-6632.1999.tb08103.x.

McEwen, B. S., \& Stellar, E. (1993). Stress and the individual: Mechanisms leading to disease. Archives of Internal Medicine, 153(18), 2093-2101. https://doi.org/10.1001/archinte.1993.00410180039004.

Mencarini, L., \& Tanturri, M. L. (2006). High fertility or childlessness: Micro-level determinants of reproductive behaviour in Italy. Population, 61(4), 389-415. https://doi.org/10.3917/popu.604.0463.

Messeri, P., Silverstein, M., \& Litwak, E. (1993). Choosing optimal support groups: A review and reformulation. Journal of Health and Social Behavior, 34(2), 122-137. https://doi.org/10.2307/2137239.

Mills, M., \& Begall, K. (2010). Preferences for the sex-composition of children in Europe: A multilevel examination of its effect on progression to a third child. Population Studies, 64(1), 77-95. https://doi. org/10.1080/00324720903497081.

Nicholson, W. K., Asao, K., Brancati, F., Coresh, J., Pankow, J. S., \& Powe, N. R. (2006). Parity and risk of type 2 diabetes. Diabetes Care, 29(11), 2349-2354. https://doi.org/10.2337/dc06-0825.

Nicoletti, C., \& Tanturri, M. L. (2008). Differences in delaying motherhood across European Countries: Empirical evidence from the ECHP. European Journal of Population, 24(2), 157-183. https://doi. org/10.1007/s10680-008-9161-y.

Ong, A. D., Uchino, B. N., \& Wethington, E. (2016). Loneliness and health in older adults: A mini-review and synthesis. Gerontology, 62(4), 443-449. https://doi.org/10.1159/000441651. 
Österle, A. (2010). Long-term care in central and south-Eastern Europe: Challenges and perspectives in addressing a "new" social risk. Social Policy and Administration, 44, 461-480. https://doi.org/10.111 1/j.1467-9515.2010.00723.x.

Österle, A. (2012). Long-term care financing in Central Eastern Europe. In J. Costa-Font \& C. Courbage (Eds.), Financing long-term care in Europe: Institutions, markets and models (pp. 236-253). London: Palgrave Macmillan. https://doi.org/10.1057/9780230349193_13.

Parikh, N. I., Cnattingius, S., Dickman, P. W., Mittleman, M. A., Ludvigsson, J. F., \& Ingelsson, E. (2010). Parity and risk of later-life maternal cardiovascular disease. American Heart Journal, 159(2), 215221.e6. https://doi.org/10.1016/j.ahj.2009.11.017.

Penning, M. J., Liu, G., \& Chou, P. H. B. (2014). Measuring loneliness among middle-aged and older adults: The UCLA and De Jong Gierveld loneliness scales. Social Indicators Research, 118(3), 11471166. https://doi.org/10.1007/s11205-013-0461-1.

Peplau, L. A., \& Perlman, D. (1982). Perspectives on loneliness. In L. A. Peplau \& D. Perlman (Eds.), Loneliness: A sourcebook of current theory, research and therapy (pp. 1-18). New York: Wiley.

Philipov, D., \& Kohler, H.-P. (2001). Tempo effects in the fertility decline in Eastern Europe: Evidence from Bulgaria, the Czech Republic, Hungary, Poland, and Russia. European Journal of Population, 17(1), 37-60. https://doi.org/10.1023/A:1010740213453.

Pinquart, M. (2003). Loneliness in married, widowed, divorced, and never-married older adults. Journal of Social and Personal Relationships, 20(1), 31-53. https://doi.org/10.1177/02654075030201002.

Pinquart, M., \& Sörensen, S. (2001). Influences on loneliness in older adults: A meta-analysis. Basic and Applied Social Psychology, 23(4), 245-266. https://doi.org/10.1207/S15324834BASP2304_2.

Pollard, M. S., \& Morgan, S. P. (2002). Emerging parental indifference? Sex composition of children and the third birth. American Sociological Review, 67(4), 600-613. https://doi.org/10.2307/3088947.

Read, S., Grundy, E., \& Wolf, D. A. (2011). Fertility history, health, and health changes in later life: A panel study of British women and men born 1923-49. Population Studies, 65(2), 201-215. https://doi. org/10.1080/00324728.2011.572654.

Routasalo, P. E., Savikko, N., Tilvis, R. S., Strandberg, T. E., \& Pitkälä, K. H. (2006). Social contacts and their relationship to loneliness among aged people-A population-based study. Gerontology, 52(3), 181-187. https://doi.org/10.1159/000091828.

Saraceno, C. (2010). Social inequalities in facing old-age dependency: A bi-generational perspective. Journal of European Social Policy, 20(1), 32-44. https://doi.org/10.1177/0958928709352540.

Saraceno, C., \& Keck, W. (2011). Towards an integrated approach for the analysis of gender equity in policies supporting paid work and care responsibilities. Demographic Research, S11(11), 371-406. https:// doi.org/10.4054/DemRes.2011.25.11.

Sobotka, T. (2003). Re-emerging diversity: Rapid fertility changes in Central and Eastern Europe after the collapse of the communist regimes. Population, 58(4-5), 451-486. https://doi.org/10.3917/ popu.304.0511.

Stevens, N., \& Westerhof, G. J. (2006). Marriage, social integration, and loneliness in the second half of life: A comparison of Dutch and German men and women. Research on Aging, 28(6), 713-729. https:// doi.org/10.1177/0164027506291747.

Tosi, M., \& Grundy, E. (2018). Returns home by children and changes in parents' well-being in Europe. Social Science and Medicine, 200, 99-106. https://doi.org/10.1016/j.socscimed.2018.01.016.

Tosi, M., \& Grundy, E. (2019). Intergenerational contacts and depressive symptoms among older parents in Eastern Europe. Aging and Mental Health, 23(6), 686-692. https://doi.org/10.1080/13607 863.2018.1442412.

Uhlenberg, P., \& Cooney, T. M. (1990). Family size and mother-child relations in later life. The Gerontologist, 30(5), 618-625. https://doi.org/10.1093/geront/30.5.618.

Van den Broek, T. (2017). Gender differences in the correlates of loneliness among Japanese persons aged 50-70. Australasian Journal on Ageing, 36(3), 234-237. https://doi.org/10.1111/ajag.12448.

Van den Broek, T., \& Grundy, E. (2017). Loneliness among Polish migrants in the Netherlands: The impact of presence and location of partners and offspring. Demographic Research, 37(23), 727-742. https:// doi.org/10.4054/DemRes.2017.37.23.

Van den Broek, T., Tosi, M., \& Grundy, E. (2019). Offspring and later-life loneliness in Eastern and Western Europe. Journal of Family Research, 31(2), 199-215. https://doi.org/10.3224/zff.v31i2.05.

Vandenheede, H., Deboosere, P., Gadeyne, S., \& De Spiegelaere, M. (2012). The associations between nationality, fertility history and diabetes-related mortality: A retrospective cohort study in the Brussels-Capital Region (2001-2005). Journal of Public Health, 34(1), 100-107. https://doi.org/10.1093/ pubmed/fdr045. 
Victor, C. R., Scrambler, S. J., Bowling, A., \& Bond, J. (2005). The prevalence of, and risk factors for, loneliness in later life: a survey of older people in Great Britain. Ageing and Society, 25(6), 357-375. https ://doi.org/10.1017/S0144686X04003332.

Vikat, A., Spéder, Z., Beets, G., Billari, F., Bühler, C., Aline, D., et al. (2007). Generations and Gender Survey (GGS): Towards a better understanding of relationships and processes in the life course. Demographic Research, 17(14), 389-440. https://doi.org/10.4054/DemRes.2007.17.14.

Vozikaki, M., Papadaki, A., Linardakis, M., \& Philalithis, A. (2018). Loneliness among older European adults: Results from the Survey of Health, Aging and Retirement in Europe. Journal of Public Health, 26(6), 613-624. https://doi.org/10.1007/s10389-018-0916-6.

Weeks, D. G., Michela, J. L., Peplau, L. A., \& Bragg, M. E. (1980). Relation between loneliness and depression: A structural equation analysis. Journal of Personality and Social Psychology, 9(5), 1238-1244. https://doi.org/10.1037/h0077709.

Weiss, R. S. (1973). Loneliness: The experience of emotional and social isolation. Cambridge, MA: MIT Press.

White, H. (1980). A heteroskedasticity-consistent covariance matrix estimator and a direct test for heteroskedasticity. Econometrica, 48(4), 817-838. https://doi.org/10.2307/1912934.

White, L., \& Edwards, J. N. (1990). Emptying the nest and parental well-being: An analysis of national panel data. American Sociological Review, 55(2), 235-242. https://doi.org/10.2307/2095629.

Wolff, J. L., \& Kasper, J. D. (2006). Caregivers of frail elders: Updating a national profile. The Gerontologist, 46(3), 344-356. https://doi.org/10.1093/geront/46.3.344.

Yang, K., \& Victor, C. (2011). Age and loneliness in 25 European nations. Ageing and Society, 31(08), 1368-1388. https://doi.org/10.1017/S0144686X1000139X.

Zhang, Z., \& Hayward, M. D. (2001). Childlessness and the psychological well-being of older persons. The Journals of Gerontology Series B: Psychological Sciences and Social Sciences, 56B(5), S311-S320. https://doi.org/10.1093/geronb/56.5.S311.

Publisher's Note Springer Nature remains neutral with regard to jurisdictional claims in published maps and institutional affiliations. 